\title{
Embracing Identity in Peer Review
}

\author{
An inclusive, diverse, and equitable peer review system should recognize \\ and embrace the identities of the involved actors-authors, referees, and \\ editors-and not expect any individual to offer a "view from nowhere."
}

\author{
By Daniel Ucko
}

6 'What do we want? Evidence-based science! When do we want it? After peer review!" This unusual chant-often heard at the "March for Science" demonstrations held around the world since 2017-expressed the high regard the demonstrators had for peer review as the gold standard for certifying research. As a long-standing editor of Physical Review Letters [1] and as a philosopher researching peer review, I believe that peer review is an indispensable aspect of the scientific process. However, peer review could certainly be made more diverse, equitable, and inclusive. I argue that achieving such a goal requires embracing the identities of all involved actors while giving up the unrealistic expectation that any of them can offer a perfectly objective view.

The role of identity was the focus of the 2021 Peer Review Week (see Research News: Reviewing Peer Review), which brought

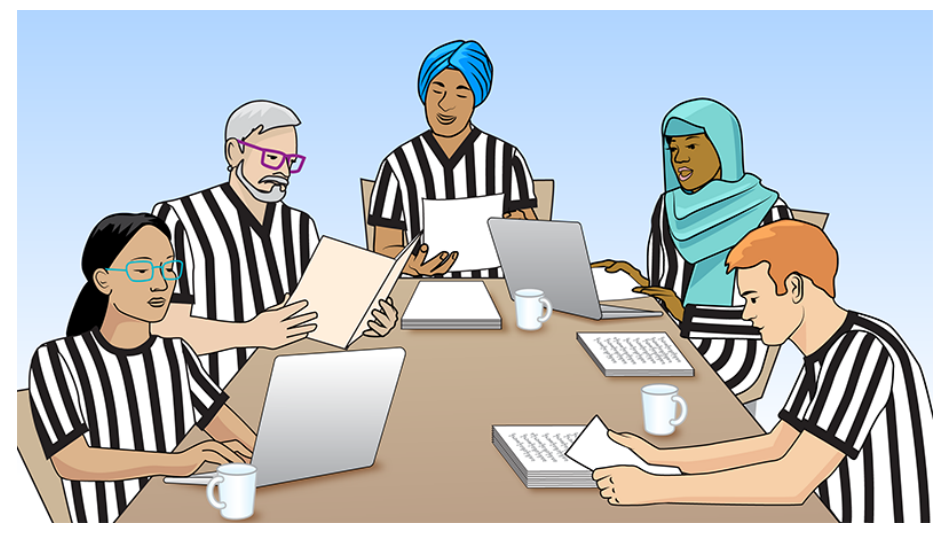

Credit: APS/Carin Cain together individuals and organizations involved in scholarly publishing. In the context of peer review, identity is often regarded as a factor to be corrected for, with the idea that the review should be as uncontaminated by subjectivity as possible. This attitude is, in my view, unrealistic and unproductive. Academic research is a social process whose participants bring their identities, and their perspectives, with them. Rather than treating these perspectives as unwanted bias, we should draw from the strength that a multiplication of perspectives can provide.

Currently, publishers are exploring peer review strategies that broadly fit into two categories. One centers on confidentiality, using anonymity strategically to gain reviewer candor and to shield authors against bias. The second champions openness, eschewing anonymity and instead sharing referee identities and reports, with the goal of preventing bad actors from hiding in the dark. These two strategies, while seemingly opposed, are employed for the same reason: to make the review process objective by either eliminating the reviewers' personalities or by holding the reviewers to account, in the hope that they move beyond a subjective view to a "view from nowhere" [2]. These efforts feed into a narrative of objectivity as being delocalized, universal, and purely rational. Its opposite, subjectivity, is instead typically described as being situated, personal, and prone to emotions and biases [3].

I argue that the myth of objectivity that underpins both approaches is an illusion. Moreover, it's a harmful one, as it discourages seeking out a variety of perspectives. This limitation has demonstrably damaged scientific progress. For 
example, in primatology, a male-dominated research community found patriarchal familial structures mirroring Victorian family values in great apes-a view that was dismantled as more women entered the field [4].

What we instead need is a more realistic view of the scientific persona and a new meaning of objectivity. I do not propose to give up on objectivity entirely; science, after all, relies on the notion of a shared external world about which we can communicate meaningful things to each other. But a new view of objectivity can be constructed following the ideas of philosopher of science Helen Longino. For her, science is the interactive process of exposing scientific results to transformative criticism from practitioners with shared values. This process elevates individual results to accumulated knowledge. Crucially, she notes that, to be successful, this transformative criticism must come from a variety of perspectives, all of which must come from people who have an equal share of intellectual authority [5].

This notion of transformative criticism offers a way for scientists to develop a new sense of objectivity that is communally informed, shifting the focus from individuals to collective interactions. It also suggests courses of action. Journals, for instance, should strive to achieve more diverse participation by expanding their reviewer pools and encouraging submissions from a wider range of authors. However, by the time the paper reaches the journal, opportunities for effective change have already been missed. We need an attitude adjustment to be stimulated from the very early training stages of academic careers, through discussions and activities that promote the value of a diversity of perspectives instead of the mirage of objectivity. To truly address inequities in peer review, we must recognize that it does not begin and end with the submission and publication of a manuscript, but also includes steps like project funding, the discussion of hypotheses and methods, the postpublication reception of the work, and the development of new research that builds on it. Stimulating such profound changes in the attitude toward peer review requires acting at the very early training stages of academic careers, through discussions and activities that promote the value of a diversity of perspectives instead of the mirage of objectivity.

This holistic view of peer review, in which objectivity stems from the multiplication of perspectives, holds the key to better journal peer review.

Daniel Ucko: APS Editorial Office, Ridge, NY, USA

\section{REFERENCES}

1. Editor Note: Both Physical Review Letters and Physics are published by the American Physical Society.

2. For a discussion of this sense of objectivity see, for instance, $\mathrm{T}$. Nagel, The View from Nowhere (Oxford University Press, Oxford, 1989), p. 14-17.

3. E. A. Lloyd, "Objectivity and the Double Standard for Feminist Epistemologies," Synthese 104, 351 (1995).

4. D. J. Haraway, "Primatology is Politics by Other Means," PSA: Proceedings of the Biennial Meeting of the Philosophy of Science Association, Vol. 1984 (University of Chicago Press, Chicago, 1984), p. 489-524.

5. H. E. Longino, Science as Social Knowledge: Values and Objectivity in Scientific Inquiry (Princeton University Press, Princeton, 1990). 